\title{
Lymphocele or Seroma After Modified Radical Mastectomy for Breast Cancer: Systematic Review and Meta-analysis.
}

\author{
Adrien CRESTANI ( $\square$ adriencrestani@hotmail.fr) \\ Institute Curie \\ MAHIOU Katia \\ Institute Curie \\ BODET Marie-Lucile \\ Institute Curie \\ ROOSEN Alice \\ Institute Curie \\ BONNEAU Claire \\ Institute Curie \\ ROUZIER Roman \\ Institute Curie
}

\section{Research Article}

Keywords: Breast cancer, breast surgery, seroma, lymphocele, mastectomy, drainage

Posted Date: January 18th, 2022

DOI: https://doi.org/10.21203/rs.3.rs-1188507/v1

License: (c) (1) This work is licensed under a Creative Commons Attribution 4.0 International License. Read Full License 


\section{Abstract}

Seroma or lymphocele remains the most common complication after mastectomy and lymphadenectomy for breast cancer. Many different techniques are available to prevent this complication. We searched MEDLINE, clinicaltrials.gov, Cochrane Library, and Web of Science databases for publications addressing the issue of prevention of lymphocele or seroma after mastectomy and axillary lymphadenectomy. Quality was assessed using a standardised tool. Incidence of seroma or lymphocele were collected. Fifteen randomized controlled trials including a total of 1,766 patients undergoing radical mastectomy and axillary lymphadenectomy for breast cancer were retrieved. The incidence of lymphocele or seroma in the study population was $24.2 \%$ (411/1698): $25.2 \%$ (232/920) in the test groups and 23.0\% (179/778) in the control groups. Neither modification of surgical technique $(\mathrm{RR}=0.86 ; 95 \% \mathrm{Cl}[0.72,1.03])$ nor application of a medical treatment $(\mathrm{RR}=0.96 ; 95 \% \mathrm{Cl}[0.72,1.29])$ was effective in preventing lymphocele. On the contrary, decreasing the drainage time increased the risk of lymphocele $(R R=1.88 ; 95 \% \mathrm{Cl}[1.43$, 2.48). To conclude, despite the heterogeneity of study designs, drainage appears to be the most effective technique.

\section{Introduction}

Axillary lymph node dissection (ALND) and mastectomy are performed as part of the surgical management of breast cancer and are associated with significant morbidity, as $70 \%$ of patients experience complications ${ }^{1,2}$.

Seromas or lymphoceles are the most common complication of these procedures and can delay local healing and initiation of adjuvant therapy. They are also a source of discomfort for patients. Many techniques have been developed to decrease the risk of seroma formation: wound drainage ${ }^{3}$, reduction of the dead space by flap fixation ${ }^{4}$, use of various types of energy ${ }^{5}$, external compression dressings ${ }^{6}$, shoulder immobilization or physical activity ${ }^{7}$, as well as numerous drugs and glues ${ }^{8-11}$.

Two previous Cochrane meta-analyses have evaluated fibrin glues and wound drainage and concluded on the inefficacy of fibrin glues and the limited efficacy of wound drainage ${ }^{3,8}$. To our knowledge, no meta-analysis has compared all proposed techniques for seroma prevention after mastectomy and axillary lymphadenectomy.

The objective of this meta-analysis was to determine the incidence of lymphocele or seroma after mastectomy and axillary lymphadenectomy based on a review of the published data by taking all techniques into account and to evaluate the efficacy of each technique.

\section{Materials And Methods}

This meta-analysis was performed in accordance with the 2009 Preferred Reporting Items for Systematic Reviews and Metaanalysis (PRISMA) guidelines and the Cochrane Collaboration recommendations ${ }^{12}$. The "Prevention of seroma after breast cancer surgery" trial was registered on the Open Science Framework (OSF) platform DOI 10.17605/OSF.IO/RFVG6.

\section{Literature search}

We searched MEDLINE, clinicaltrials.gov, Cochrane Library, and Web of Science databases for publications of randomized controlled trials (RCT) and clinical trials addressing the issue of prevention of lymphocele or seroma after mastectomy and axillary lymphadenectomy. Various combinations of the following terms were searched: "lymphocele", "lymphorrhea", "seroma", "breast cancer", "breast surgery".

\section{Eligibility criteria}

Three authors independently conducted the initial research to evaluate eligibility criteria (AC, MLB, KM). We selected randomized controlled trials and clinical trials published after January 2000 in English, including more than 50 participants, reporting the incidence of lymphocele or seroma after mastectomy and axillary lymphadenectomy for breast cancer. The latest search was performed in March 2021. 
The following publications were excluded: retrospective studies, case reports, letters to the editor, publications concerning plastic surgery, brachytherapy or radiation therapy.

\section{Data collection process and outcome measures}

Three authors independently performed data collection using a standardized data extraction table (AC, MLB, KM). The following data were extracted: author, year and country of publication, study characteristics, prevention technique, inclusion and exclusion criteria, number of patients, data necessary to build $2 \times 2$ contingency tables.

\section{Statistical analysis}

\section{Publication bias}

A funnel plot was used to visualize publication bias. The estimate of the difference between groups was pooled, depending upon the effect weights of the variance estimate determined in each trial. Egger's test was used to assed asymmetry of the funnel plot $^{13}$.

\section{Outcomes}

For dichotomous outcomes, the Mantel-Haenszel method was used for calculation of relative risk (RR) under the fixed-effect and random-effects models ${ }^{13}$. The Forest plot was used for graphic display of the results of the meta-analysis. The heterogeneity of studies was calculated using the $\mathrm{I}^{2}$ index. The $\mathrm{I}^{2}$ value was interpreted by balancing the direction and magnitude of $\mathrm{I}^{2}$ with its statistical significance, using the values in the Cochrane Handbook for Systematic Reviews of Interventions as a guide ${ }^{14}: 0 \%$ to $40 \%$ : might not be important; $30 \%$ to $60 \%$ : may represent moderate heterogeneity; $50 \%$ to $90 \%$ : may represent substantial heterogeneity; $75 \%$ to $100 \%$ : represents considerable heterogeneity. Meta-analyses with insignificant heterogeneity were calculated using the fixed-effects model ${ }^{15}$. For meta-analyses with low or moderate heterogeneity, the random-effects model was used $^{16}$. The square around the estimate represents the accuracy of the estimation (sample size) and the horizontal line represents the $95 \%$ confidence interval $(95 \% \mathrm{Cl})$.

Data were entered in an Excel file and all statistical analyses were performed using Rstudio software (RStudio, PBC, Boston, U.S.A.). A $\mathrm{P}$ value $<0.05$ was considered to be statistically significant.

\section{Quality assessment of the studies included}

We used a quality assessment tool elaborated by Hawker et al. ${ }^{17}$ in 2002 for systematic review of qualitative evidence. The scale contains nine items assessing abstract/title, introduction/aims, method/data, sampling, data analysis, ethics/bias, results, transferability and implications. Each item is rated as "good", "fair", "poor" and "very poor". Lorenc et al. ${ }^{18}$ added a graduation to this scale by assigning answers from 1 point (very poor) to 4 points (good), to provide a final score for each study (9 to 36 points). The overall quality grades were defined by the following description: grade A (high quality) 30-36 points; grade B (medium quality), 24-29 points and grade C (low quality), 9-24 points. Each of the three readers assessed the studies independently. When differences were observed, a majority agreement was reached.

\section{Results}

\section{Study selection}

The PRISMA flow diagram explaining the literature search strategy and trial selection is presented in Figure 1. Fifteen randomized controlled trials including a total of 1,766 patients undergoing radical mastectomy and axillary lymphadenectomy for breast cancer were retrieved from the electronic databases. Analysis was based on 822 patients in the test groups and 778 patients in control groups. The characteristics of the trials included in this meta-analysis are provided in Table 1 . The technique used in each article is described in Table 1. The incidence of lymphocele or seroma in the study population was $24.2 \%$ (411/1698): $25.2 \%$ $(232 / 920)$ in the test groups and $23.0 \%(179 / 778)$ in the control groups. 
As the study by Dalberg et al. ${ }^{19}$ compared two different techniques in two separate groups of patients, we decided to divide this study into one group treated by drainage and the other group treated by the fascia preservation surgical technique.

\section{Study characteristics}

Study characteristics are described in Table 1. Two of the 15 studies concerned lymphoceles ${ }^{20,21}$, while all of the other studies concerned seromas. Six studies did not specify their definition of seroma, 9 studies reported a clinical definition of seroma or lymphocele (palpation, clinical examination, needle aspiration) and one study used an ultrasound definition. Five studies reported statistically significant results ${ }^{19,22-25}$.

\section{Publication bias}

The funnel plot did not show any asymmetry (Supplemental Figure 1). Egger's test did not reveal any publication bias $(p=0.36)$.

\section{Prevention of seroma regardless of the technique}

Significant heterogeneity was observed between the 15 studies $\left(l^{2}=73 \%, p<0.01\right)$. Therefore, in the random effects model, none of the techniques allowed statistically significant prevention of lymphocele or seroma formation $(\mathrm{RR}=1.23 ; 95 \% \mathrm{Cl}[0.92,1.65]$; Figure 2).

\section{Prevention of seroma according to the various techniques}

Medical treatment:-

Significant heterogeneity was observed between the 6 studies $\left(I^{2}=68 \%, p<0.01\right) 21,22,26-28$. Therefore, in the random effects model, medical treatments did not allow statistically significant prevention of lymphocele or seroma (RR=0.96; $95 \% \mathrm{Cl}[0.72,1.29]$; Figure 3)

\section{Surgical techniques:}

Significant heterogeneity was observed between the 4 studies $\left(I^{2}=77 \%, p<0.01\right) \quad 19,23,29,30$. Therefore, in the random effects model, no specific surgical technique allowed statistically significant prevention of lymphocele or seroma $(\mathrm{RR}=0.86 ; 95 \% \mathrm{Cl}[0.72,1.03]$; Figure 4)

\section{Modification of the drainage process:}

No heterogeneity was observed between the 4 studies $\left(I^{2}=0 \%, p=0.83\right)^{19,25,31,32}$. Therefore, in the fixed effects model, the risk of lymphocele or seroma was significantly increased by modification of the drainage technique $(\mathrm{RR}=1.88 ; 95 \% \mathrm{Cl}[1.43,2.48]$; Figure 5)

Other techniques:

One study that investigated prevention of lymphocele or seroma using fibrin glue ${ }^{33}$ found this technique to be statistically ineffective (RR=1.36; 95\% Cl [0.77; 2.38]).

One study that investigated prevention of lymphocele or seroma using physical activity and manual lymphatic drainage ${ }^{34}$ found these technique to be statistically ineffective (RR=1.67; $95 \% \mathrm{Cl}[0.44 ; 6.29])$.

\section{Study quality}

The results of the quality assessment are described in Supplemental table 1. One study was considered to present high quality (Grade A), 8 studies were considered to present medium quality (Grade B), and 6 studies were considered to present low quality (Grade C). 


\section{Discussion}

This work represents the first meta-analysis of all techniques proposed for the prevention of lymphocele formation after mastectomy and axillary lymphadenectomy in prospective randomized controlled trials and clinical trials. Global analysis of all of the various techniques showed that they were not effective to prevent lymphocele formation $(\mathrm{RR}=1.23 ; 95 \% \mathrm{Cl}[0.92,1.65])$. Analysis of studies based on modification of the drainage technique showed a negative effect on seroma prevention ( $R R=1.88$; $95 \% \mathrm{Cl}[1.43,2.48])$. Glues and drugs were not effective (RR=1.36; $95 \% \mathrm{Cl}[0.77 ; 2.38], \mathrm{RR}=0.96 ; 95 \% \mathrm{Cl}[0.72,1.29])$. The overall quality of these items was moderate with 8 items presenting average quality, 6 items presenting low quality, and only one item presenting high quality.

In this study, we chose to restrict our analysis to the population at high risk of lymphocele or seroma ${ }^{35}$. In our meta-analysis, regardless of the definitions and techniques used to prevent seroma or lymphocele, the overall incidence of these complications was $24.2 \%$ (411/1698): $25.2 \%$ (232/920) in the test groups and $23.0 \%$ (179/778) in the control groups. The reported seroma or lymphocele incidence is dependent on the author's definition of seroma or lymphocele and the method of detection used. Risk factors for seroma formation include age, body mass index (BMI), tumor size, use of neoadjuvant chemotherapy, type of surgery (MRM versus breast-conserving surgery) ${ }^{35}$, axillary lymph node status, axillary lymph nodes sampled or removed, and subsequently the extent of surgical dead space produced ${ }^{36}$. In our meta-analysis, only one article ${ }^{33}$ considered neoadjuvant chemotherapy to be an exclusion criterion, while most of other studies did not mention neoadjuvant chemotherapy. Other risk factors, except for the type of surgery, were not well documented. This lack of information on risk factors may result in an incidence bias.

The various techniques tested to reduce seroma or lymphocele after breast surgery are based on the different physiological theories. Six studies tested a drug for prevention of seromas. These drugs inhibit the inflammatory or immunopathological response, which is considered to play a role in seroma formation ${ }^{36}$. Four studies evaluated a specific surgical procedure. A French multicenter, superiority, randomized controlled trial, compared seroma formation using quilting suture versus conventional closure with drainage in 320 patients undergoing mastectomy ${ }^{37}$, results have not yet been published. A meta-analysis by Sajid et al. studied application of fibrin glue under skin flaps to prevent seroma-related morbidity following breast and axillary surgery ${ }^{8}$, but this technique failed to reduce the incidence of postoperative seroma (RR: 1.02; 95\% Cl: $0.90-1.16$, P value $=0.73$ ).

Four studies included in our meta-analysis evaluated modification of the drainage technique. Since 1947 and the first description of drainage after axillary dissection for breast cancer by Murphey ${ }^{38}$, drainage is the technique most commonly used to prevent lymphocele or seroma after radical mastectomy and axillary lymphadenectomy. In 2013, a Cochrane meta-analysis by Thomson et al. ${ }^{3}$ compared wound drainage versus no wound drainage after axillary lymphadenectomy for breast carcinoma. Seven RCTs including 960 participants were identified. The quality of trials was generally low, with several studies at risk of selection bias, and no studies used blinding during treatment or outcome assessment. There was a high level of statistical variation between studies, which therefore reduces the reliability of the evidence. The $\mathrm{R}$ for seroma formation was 0.46 ([95\% Cl: 0.23 to 0.91$], \mathrm{P}=0.03$ ) in favor of a reduced incidence of seroma in participants with drains inserted.

Finally, wound drainage appears to be the most effective way to prevent seroma, although no consensus has been reached concerning the optimal duration of drainage. However, persistence of foreign devices under the skin could predispose to surgical site infection. Surgical site infection is one of the possible complications after breast cancer surgery, causing significant morbidity, additional costs and which can delay initiation of adjuvant therapy. In Reiffel's review ${ }^{39}$ of the potential association between closed-suction drains and surgical site infection, few studies suggested an increased risk of surgical site infection associated with drain placement and no studies attributed a decreased incidence of surgical site infection (including organ/space surgical site infection) with drain placement.

\section{Conclusion}

The lack of consensus concerning the definition of lymphocele or seroma is probably responsible for the heterogeneity of seroma incidence reported in the literature and the inefficacy of the techniques proposed for seroma prevention after breast cancer

Page 5/14 
surgery. However, drainage is the most effective technique currently available.

\section{Abbreviations}

ALND: Axillary lymph node dissection

BMI: body mass index

Cl: confidence interval

MRM: modified radical mastectomy

OSF: Open Science Framework

RCT: Randomized control trial

RR: relative risk

\section{Declarations}

Declarations of interest: The authors have no conflicts of interest to declare that are relevant to the content of this article.

Funding: No funds, grants, or other support was received.

Acknowledgments: none

Conflict of interest

The authors declare that they have no conflict of interest. The authors declare that no foundations are involved in the study.

Research involving human participants and/or animals N/A

Informed consent: For this type of study, formal consent is not required

Authors contributions :

CA: Design of the work

CA, MK, BM-L: drafting

MK: analysis

CA: data acquisition

$\mathrm{RA}, \mathrm{BC}$ : reviewing process

RR: project supervision.

Competing interests:

The author(s) declare no competing interests.

\section{References}

1. Roses DF, Brooks AD, Harris MN, Shapiro RL, Mitnick J. Complications of Level I and II Axillary Dissection in the Treatment of Carcinoma of the Breast: Ann Surg. 1999 Aug;230(2):194. 
2. Lucci A, McCall LM, Beitsch PD, Whitworth PW, Reintgen DS, Blumencranz PW, Leitch AM, Saha S, Hunt KK, Giuliano AE; American College of Surgeons Oncology Group. Surgical Complications Associated With Sentinel Lymph Node Dissection (SLND) Plus Axillary Lymph Node Dissection Compared With SLND Alone in the American College of Surgeons Oncology Group Trial Z0011. J Clin Oncol. 2007 Aug 20;25(24):3657-63

3. Thomson DR, Sadideen H, Furniss D. Wound drainage after axillary dissection for carcinoma of the breast. Cochrane Database Syst Rev. 2013 Oct 20;(10):CD006823.

4. Granzier RWY, van Bastelaar J, van Kuijk SMJ, Hintzen KFH, Heymans C, Theunissen LLB, et al. Reducing seroma formation and its sequelae after mastectomy by closure of the dead space: The interim analysis of a multi-center, double-blind randomized controlled trial (SAM trial). Breast. 2019 Aug;46:816.

5. Lumachi F, Basso SMM, Santeufemia DA, Bonamini M, Chiara GB. Ultrasonic dissection system technology in breast cancer: a case-control study in a large cohort of patients requiring axillary dissection. Breast Cancer Res Treat. 2013 Nov;142(2):399404.

6. O'Hea BJ, Ho MN, Petrek JA. External compression dressing versus standard dressing after axillary lymphadenectomy. Am J Surg. 1999 Jun;177(6):4503.

7. Chen SC, Chen MF. Timing of shoulder exercise after modified radical mastectomy: a prospective study. Chang Yi Xue Za Zhi. 1999 Jun;22(1):3743.

8. Sajid MS, Hutson KH, Rapisarda IF, Bonomi R. Fibrin glue instillation under skin flaps to prevent seroma-related morbidity following breast and axillary surgery. Cochrane Database Syst Rev. 2013 May 31;(5):CD009557.

9. Suarez-Kelly LP, Pasley WH, Clayton EJ, Povoski SP, Carson WE, Rudolph R. Effect of topical microporous polysaccharide hemospheres on the duration and amount of fluid drainage following mastectomy: a prospective randomized clinical trial. BMC Cancer. 2019 Jan 23;19(1):99.

10. Gauthier T, Garuchet-Bigot A, Marin B, Mollard J, Loum O, Fermeaux V, et al. Lanreotide Autogel 90 mg and lymphorrhea prevention after axillary node dissection in breast cancer: a phase III double blind, randomized, placebo-controlled trial. Eur J Surg Oncol. 2012 Oct;38(10):9029.

11. Benevento R, Santoriello A, Pellino G, Sciaudone G, Candilio G, De Fatico GS, et al. The effects of low-thrombin fibrin sealant on wound serous drainage, seroma formation and length of postoperative stay in patients undergoing axillary node dissection for breast cancer. A randomized controlled trial. Int J Surg. 2014 Nov;12(11):12105.

12. Moher D, Liberati A, Tetzlaff J, Altman DG, PRISMA Group. Preferred reporting items for systematic reviews and metaanalyses: the PRISMA statement. PLoS Med. 2009 Jul 21;6(7):e1000097.

13. Egger M, Davey Smith G, Schneider M, Minder C. Bias in meta-analysis detected by a simple, graphical test. BMJ. 1997 Sep 13;315(7109):62934.

14. Higgins JPT, Altman DG, Gøtzsche PC, Jüni P, Moher D, Oxman AD, et al. The Cochrane Collaboration's tool for assessing risk of bias in randomised trials. BMJ. 2011 Oct 18;343:d5928.

15. Demets DL. Methods for combining randomized clinical trials: strengths and limitations. Stat Med.1987 May;6(3):34150.

16. DerSimonian R, Laird N. Meta-analysis in clinical trials. Control Clin Trials. 1986 Sep;7(3):17788.

17. Hawker S, Payne S, Kerr C, Hardey M, Powell J. Appraising the evidence: reviewing disparate data systematically. Qual Health Res. 2002 Nov;12(9):128499.

18. Lorenc T, Petticrew M, Whitehead M, Neary D, Clayton S, Wright K, et al. Crime, fear of crime and mental health: synthesis of theory and systematic reviews of interventions and qualitative evidence. Public Health Res. 2014 Mar;2(2):1398.

19. Dalberg K, Johansson H, Signomklao T, Rutqvist LE, Bergkvist L, Frisell J, et al. A randomised study of axillary drainage and pectoral fascia preservation after mastectomy for breast cancer. Eur J Surg Oncol. 2004 Aug;30(6):6029.

20. Gupta R, Pate K, Varshney S, Goddard J, Royle GT. A comparison of 5-day and 8-day drainage following mastectomy and axillary clearance. Eur J Surg Oncol. $2001 \mathrm{Feb} ; 27(1): 2630$.

21. Chéreau E, Uzan C, Boutmy-Deslandes E, Zohar S, Bézu C, Mazouni C, et al. Evaluation of the Effects of Pasireotide LAR Administration on Lymphocele Prevention after Axillary Node Dissection for Breast Cancer: Results of a Randomized NonComparative Phase 2 Study. PLoS One. 2016;11(6):e0156096. 
22. Kong D, Liu Y, Li Z, Cui Q, Wang K, Wu K, et al. OK-432 (Sapylin) Reduces Seroma Formation After Axillary Lymphadenectomy in Breast Cancer. J Investig Surg. 2017 Feb;30(1):15.

23. Gong Y, Xu J, Shao J, Cheng H, Wu X, Zhao D, et al. Prevention of seroma formation after mastectomy and axillary dissection by lymph vessel ligation and dead space closure: a randomized trial. Am J Surg. 2010 Sep;200(3):3526.

24. Rice DC, Morris SM, Sarr MG, Farnell MB, van Heerden JA, Grant CS, et al. Intraoperative topical tetracycline sclerotherapy following mastectomy: a prospective, randomized trial. J Surg Oncol. 2000 Apr;73(4):2247.

25. Gupta R, Pate K, Varshney S, Goddard J, Royle GT. A comparison of 5-day and 8-day drainage following mastectomy and axillary clearance. Eur J Surg Oncol. 2001 Feb;27(1):2630.

26. Rice DC, Morris SM, Sarr MG, Farnell MB, van Heerden JA, Grant CS, et al. Intraoperative topical tetracycline sclerotherapy following mastectomy: a prospective, randomized trial. J Surg Oncol. 2000 Apr;73(4):2247.

27. Cabaluna ND, Uy GB, Galicia RM, Cortez SC, Yray MDS, Buckley BS. A randomized, double-blinded placebo-controlled clinical trial of the routine use of preoperative antibiotic prophylaxis in modified radical mastectomy. World J Surg. 2013 Jan;37(1):5966.

28. Garza-Gangemi AM, Barquet-Muñoz SA, Villarreal-Colín SP, Medina-Franco H, Cortés-González R, Vilar-Compte D, et al. Randomized Phase II Study of Talc Versus lodopovidone for the Prevention of Seroma Formation Following Modified Radical Mastectomy. Rev Investig Clin Organo Hosp Enfermedades Nutr. 2015;67(6):35765.

29. Khan MA. Effect Of Preoperative Intravenous Steroids On Seroma Formation After Modified Radical Mastectomy. J Ayub Med Coll Abbottabad. 2017;29(2):20710.

30. Ribeiro GHFP, Kerr LM, Haikel RL, Peres SV, Matthes AGZ, Depieri Michelli RA, et al. Modified radical mastectomy: a pilot clinical trial comparing the use of conventional electric scalpel and harmonic scalpel. Int J Surg. 2013;11(6):496500.

31. Khan S, Khan S, Chawla T, Murtaza G. Harmonic scalpel versus electrocautery dissection in modified radical mastectomy: a randomized controlled trial. Ann Surg Oncol. 2014;21(3):80814.

32. Ulusoy AN, Polat C, Alvur M, Kandemir B, Bulut F. Effect of fibrin glue on lymphatic drainage and on drain removal time after modified radical mastectomy: a prospective randomized study. Breast J. 2003;9(5):3936.

33. Kuroi K, Shimozuma K, Taguchi T, Imai H, Yamashiro H, Ohsumi S, et al. Evidence-based risk factors for seroma formation in breast surgery. Jpn J Clin Oncol. 2006;36(4):197206.

34. McCaul JA, Aslaam A, Spooner RJ, Louden I, Cavanagh T, Purushotham AD. Aetiology of seroma formation in patients undergoing surgery for breast cancer. Breast. 2000 Jun;9(3):1448.

35. Ouldamer L, Bonastre J, Brunet-Houdard S, Body G, Giraudeau B, Caille A. Dead space closure with quilting suture versus conventional closure with drainage for the prevention of seroma after mastectomy for breast cancer (QUISERMAS): protocol for a multicentre randomised controlled trial. BMJ Open. 2016 Apr 4;6(4):e009903.

36. Murphey DR. The use of atmospheric pressure in obliterating axillary dead space following radical mastectomy. South Surg. 1947 Jun;13(6):3725.

37. Reiffel AJ, Barie PS, Spector JA. A multi-disciplinary review of the potential association between closed-suction drains and surgical site infection. Surg Infect. 2013 Jun;14(3):24469.

38. Chintamani, Singhal V, Singh J, Bansal A, Saxena S. Half versus full vacuum suction drainage after modified radical mastectomy for breast cancer- a prospective randomized clinical trial[ISRCTN24484328]. BMC Cancer. 2005 Jan 27;5:11.

39. Clegg-Lamptey JNA, Dakubo JCB, Hodasi WM. Comparison of four-day and ten-day post-mastectomy passive drainage in Accra, Ghana. East Afr Med J. 2007 Dec;84(12):5615.

40. de Oliveira MMF, de Rezende LF, do Amaral MTP, Pinto e Silva MP, Morais SS, Gurgel MSC. Manual lymphatic drainage versus exercise in the early postoperative period for breast cancer. Physiother Theory Pract. 2014 Aug;30(6):3849.

\section{Tables}

Table 1. Characteristics of included stories 


\begin{tabular}{|c|c|c|c|c|c|c|c|c|c|}
\hline Authors & Year & $\begin{array}{l}\text { Technique } \\
\text { used }\end{array}$ & Term used & $\begin{array}{l}\text { Seroma } \\
\text { definition }\end{array}$ & $\begin{array}{l}\text { Number } \\
\text { of } \\
\text { patients }\end{array}$ & $\begin{array}{l}\text { Incidence } \\
\text { of seroma, } \\
\text { study } \\
\text { population } \\
\mathrm{n} / \mathrm{N}(\%)\end{array}$ & $\begin{array}{l}\text { Incidence } \\
\text { of } \\
\text { seroma: } \\
\text { test } \\
\text { group } \\
\text { n/N(\%) }\end{array}$ & $\begin{array}{l}\text { Incidence } \\
\text { of } \\
\text { seroma: } \\
\text { control } \\
\text { group } \\
\text { n/N(\%) }\end{array}$ & $\begin{array}{l}\text { p- } \\
\text { value }\end{array}$ \\
\hline $\begin{array}{l}\text { Rice et al. } \\
\text { (26) }\end{array}$ & 2000 & Drug & Seroma & 0 & 62 & $23 / 62(37)$ & $\begin{array}{l}16 / 30 \\
(53)\end{array}$ & 7/32 (22) & 0.01 \\
\hline $\begin{array}{l}\text { Gupta et al. } \\
(20)\end{array}$ & 2001 & Drain & Lymphocele & Palpation & 121 & $\begin{array}{l}47 / 121 \\
(38)\end{array}$ & $\begin{array}{l}31 / 64 \\
(48)\end{array}$ & $\begin{array}{l}16 / 57 \\
(28)\end{array}$ & 0.026 \\
\hline $\begin{array}{l}\text { Ali Naki } \\
\text { Ulusoy et } \\
\text { al. (32) }\end{array}$ & 2003 & Glue & Seroma & 0 & 54 & $8 / 54$ (15) & $5 / 27(18)$ & 3/27 (11) & $>0.05$ \\
\hline \multirow[t]{2}{*}{$\begin{array}{l}\text { Dalberg et } \\
\text { al. (19) }\end{array}$} & \multirow[t]{2}{*}{2004} & Drain & \multirow[t]{2}{*}{ Seroma } & \multirow[t]{2}{*}{ Palpation } & \multirow[t]{2}{*}{247} & \multirow[t]{2}{*}{$\begin{array}{l}70 / 247 \\
(28)\end{array}$} & $\begin{array}{l}48 / 99 \\
(48)\end{array}$ & $\begin{array}{l}22 / 99 \\
(22)\end{array}$ & $<0.001$ \\
\hline & & Surgery & & & & & $\begin{array}{l}39 / 98 \\
(40)\end{array}$ & $\begin{array}{l}31 / 100 \\
(31)\end{array}$ & 0,2 \\
\hline $\begin{array}{l}\text { Chintamani } \\
\text { et al. (37) }\end{array}$ & 2005 & Drain & Seroma & 0 & 85 & $3 / 85$ (4) & $2 / 50(4)$ & 1/35 (3) & $>0.05$ \\
\hline $\begin{array}{l}\text { Clegg- } \\
\text { Lamptey et } \\
\text { al. (38) }\end{array}$ & 2007 & Drain & Seroma & Palpation & 87 & 33/87 (38) & $\begin{array}{l}21 / 45 \\
(47)\end{array}$ & $\begin{array}{l}12 / 42 \\
(29)\end{array}$ & 0.2 \\
\hline $\begin{array}{l}\text { Yiping } \\
\text { Gong et al. } \\
\text { (23) }\end{array}$ & 2010 & Surgery & Seroma & Palpation & 201 & 16/201 (8) & $\begin{array}{l}14 / 101 \\
(14)\end{array}$ & 2/100 (2) & $<0.01$ \\
\hline $\begin{array}{l}\text { Cabaluna } \\
\text { et al. (27) }\end{array}$ & 2013 & Drug & Seroma & 0 & 254 & $\begin{array}{l}35 / 148 \\
(24)\end{array}$ & $\begin{array}{l}18 / 74 \\
(24)\end{array}$ & $\begin{array}{l}17 / 74 \\
(23)\end{array}$ & 0.86 \\
\hline $\begin{array}{l}\text { Ribeiro et } \\
\text { al. (30) }\end{array}$ & 2013 & Surgery & Seroma & 0 & 94 & $21 / 94(22)$ & $8 / 49$ (16) & $\begin{array}{l}13 / 46 \\
(28)\end{array}$ & 0.16 \\
\hline $\begin{array}{l}\text { Khan S et } \\
\text { al. (31) }\end{array}$ & 2014 & Surgery & Seroma & Palpation & 150 & $\begin{array}{l}41 / 150 \\
(27)\end{array}$ & $\begin{array}{l}16 / 75 \\
(21)\end{array}$ & $\begin{array}{l}25 / 75 \\
(33)\end{array}$ & 0.07 \\
\hline $\begin{array}{l}\text { Maia Freire } \\
\text { de Oliveira } \\
\text { et al. (39) }\end{array}$ & 2014 & $\begin{array}{l}\text { Physical } \\
\text { activity }\end{array}$ & Seroma & Palpation & 96 & 33/84 (39) & $\begin{array}{l}19 / 43 \\
(44)\end{array}$ & $\begin{array}{l}14 / 41 \\
(34)\end{array}$ & 0.35 \\
\hline $\begin{array}{l}\text { Garza- } \\
\text { Gangemi et } \\
\text { al. (28) }\end{array}$ & 2015 & Drug & Seroma & Palpation & 80 & $17 / 80(21)$ & $\begin{array}{l}10 / 50 \\
(20)\end{array}$ & 7/30 (23) & 0.7 \\
\hline $\begin{array}{l}\text { Chereau et } \\
\text { al. (21) }\end{array}$ & 2016 & Drug & Lymphocele & $\begin{array}{l}\text { Palpation } \\
\text { and } \\
\text { needle } \\
\text { aspiration } \\
\text { volume }\end{array}$ & 90 & $42 / 90(47)$ & $\begin{array}{l}16 / 42 \\
(38)\end{array}$ & $\begin{array}{l}26 / 48 \\
(54)\end{array}$ & $>0.05$ \\
\hline $\begin{array}{l}\text { Kong et al. } \\
(22)\end{array}$ & 2016 & Drug & Seroma & 0 & 80 & $14 / 80(18)$ & $2 / 40(5)$ & $\begin{array}{l}12 / 40 \\
(30)\end{array}$ & $<0.01$ \\
\hline $\begin{array}{l}\text { Khan M et } \\
\text { al. (29) }\end{array}$ & 2017 & Drug & Seroma & $\begin{array}{l}\text { Palpation } \\
\text { and } \\
\text { needle } \\
\text { aspiration } \\
\text { volume } \\
\text { and } \\
\text { ultrasound }\end{array}$ & 65 & $8 / 65$ (12) & 6/33 (19) & $2 / 32$ (6) & $>0.05$ \\
\hline
\end{tabular}

Figures 




Figure 1

Preferred Reporting Items for Systematic Reviews and Meta-Analyses (PRISMA) flow diagram of literature screening and selection. 


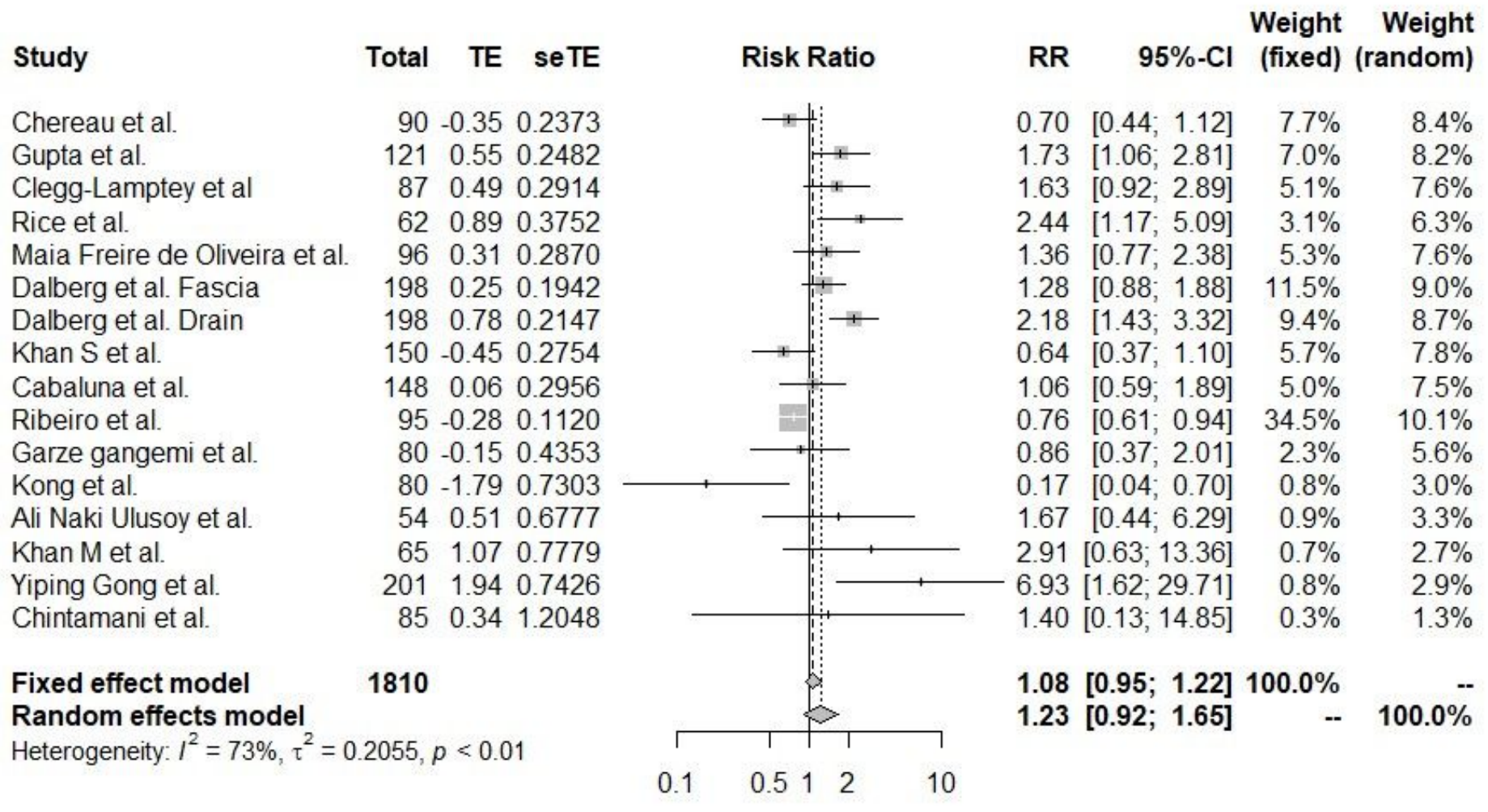

Figure 2

Forest plot for seroma incidence following application of a treatment designed to prevent lymphocele after mastectomy with axillary lymphadenectomy. Risk ratios are shown with $95 \%$ confidence intervals. 


\begin{tabular}{|c|c|c|c|c|c|c|c|c|c|c|}
\hline Study & Total & TE & seTE & & Risk Ratio & & RR & $95 \%-\mathrm{Cl}$ & $\begin{array}{r}\text { Weight } \\
\text { (fixed) }\end{array}$ & $\begin{array}{r}\text { Weight } \\
\text { (random) }\end{array}$ \\
\hline Chereau et al. & 90 & -0.35 & 0.2373 & & $\rightarrow$ & & 0.70 & {$[0.44 ; 1.12]$} & $39.4 \%$ & $23.0 \%$ \\
\hline Rice et al. & 62 & 0.89 & 0.3752 & & 1 & & 2.44 & {$[1.17 ; 5.09]$} & $15.7 \%$ & $18.9 \%$ \\
\hline Cabaluna et al. & 148 & 0.06 & 0.2956 & & & & 1.06 & {$[0.59 ; 1.89]$} & $25.4 \%$ & $21.3 \%$ \\
\hline Garze gangemi et al. & 80 & -0.15 & 0.4353 & & . & & 0.86 & {$[0.37 ; 2.01]$} & $11.7 \%$ & $17.1 \%$ \\
\hline Kong et al. & 80 & -1.79 & 0.7303 & & - & & 0.17 & {$[0.04 ; 0.70]$} & $4.2 \%$ & $10.2 \%$ \\
\hline Khan $\mathrm{M}$ et al. & 65 & 1.07 & 0.7779 & & & & 2.91 & {$[0.63 ; 13.36]$} & $3.7 \%$ & $9.5 \%$ \\
\hline \multirow{3}{*}{$\begin{array}{l}\text { Fixed effect model } \\
\text { Random effects model } \\
\text { Heterogeneity: } I^{2}=68 \%, \tau^{2}\end{array}$} & & & & & & & \multirow[t]{3}{*}{$\begin{array}{l}0.96 \\
0.99\end{array}$} & \multirow[t]{3}{*}{$\begin{array}{l}{[0.72 ; 1.29]} \\
{[0.55 ; 1.77]}\end{array}$} & \multirow[t]{3}{*}{$\begin{array}{r}100.0 \% \\
--\end{array}$} & \multirow[t]{3}{*}{$100.0 \%$} \\
\hline & $=0.32$ & $53, p$ & 0.01 & & & & & & & \\
\hline & & & & 0.1 & 0.512 & 10 & & & & \\
\hline
\end{tabular}

Figure 3

Forest plot for seroma incidence following application of a medical treatment designed to preventing lymphocele after mastectomy with axillary lymphadenectomy. Risk ratios are shown with 95\% confidence intervals. 


\begin{tabular}{|c|c|c|c|c|c|c|c|c|c|}
\hline Study & Total & TE seTE & & Risk Ratio & & RR & $95 \%-\mathrm{Cl}$ & $\begin{array}{r}\text { Weight } \\
\text { (fixed) }\end{array}$ & $\begin{array}{l}\text { Weight } \\
\text { (random) }\end{array}$ \\
\hline Dalberg et al. Fascia & 198 & $0.25 \quad 0.1942$ & & & & 1.28 & {$[0.88 ; 1.88]$} & $21.9 \%$ & $30.4 \%$ \\
\hline Khan S et al. & 150 & -0.450 .2754 & & $\rightarrow 1$ & & 0.64 & {$[0.37 ; 1.10]$} & $10.9 \%$ & $26.0 \%$ \\
\hline Ribeiro et al. & 95 & -0.280 .1120 & & $\because$ & & 0.76 & {$[0.61 ; 0.94]$} & $65.7 \%$ & $34.2 \%$ \\
\hline Yiping Gong et al. & 201 & 1.940 .7426 & & & & 6.93 & [1.62; 29.71] & $1.5 \%$ & $9.3 \%$ \\
\hline \multirow{3}{*}{$\begin{array}{l}\text { Fixed effect model } \\
\text { Random effects model } \\
\text { Heterogeneity: } I^{2}=80 \%, \tau^{2}\end{array}$} & 644 & & & 9 & & \multirow[t]{3}{*}{$\begin{array}{l}0.86 \\
1.05\end{array}$} & \multirow[t]{3}{*}{$\begin{array}{l}{[0.72 ; 1.03]} \\
{[0.62 ; 1.75]}\end{array}$} & \multirow[t]{3}{*}{$\begin{array}{r}.0 \% \\
--\end{array}$} & \multirow[t]{3}{*}{$100.0 \%$} \\
\hline & $=0.18$ & $90, p<0.01$ & Г & $T$ & 7 & & & & \\
\hline & & & 0.1 & 0.512 & 10 & & & & \\
\hline
\end{tabular}

Figure 4

Forest plot for seroma incidence following application of a surgical technique designed to prevent lymphocele after mastectomy with axillary lymphadenectomy. Risk ratios are shown with $95 \%$ confidence intervals 


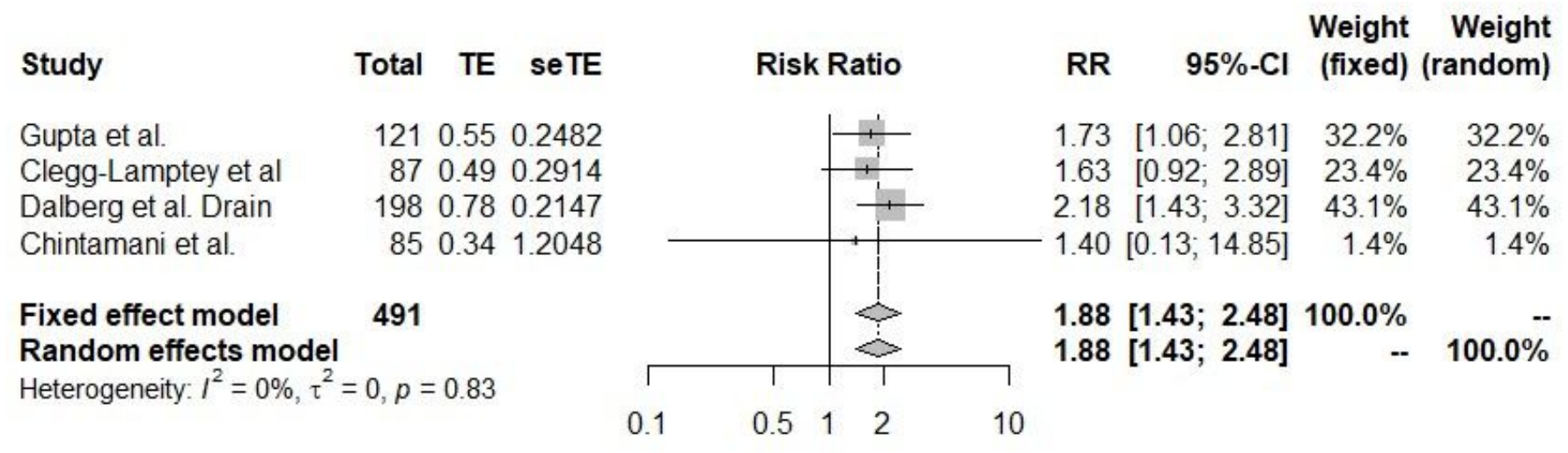

\section{Figure 5}

Forest plot for seroma incidence following application of a modified drainage method designed to prevent lymphocele after mastectomy with axillary lymphadenectomy. Risk ratios are shown with $95 \%$ confidence intervals.

\section{Supplementary Files}

This is a list of supplementary files associated with this preprint. Click to download.

- SupplementalFigure1.Funnel.jpg

- SupplementalTable1.Quality.docx 